\title{
AUTOMATION AND ROBOTICS IN CONSTRUCTION
}

\author{
STATE OF THE ART IN THE UNITED KINGDOM
}

\author{
Dr. Fikry K. Garas \\ Taylor Woodrow Construction Ltd., \\ Southall, Middlesex U.K.
}

\section{ABSTRACT}

As in a number of Western countries, the need for automation and robotic application for use in the construction industry in the U.K. has been recognised during the past ten years. The industry is experiencing increasing shortages of skilled labour and an ageing workforce. The industry is also facing demands for higher productivity and improved quality in order to meet external competition.

A number of developments covering many applications are currently in progress in some academic and industrial organisations. The range includes computer aided construction and engineering, enabling technologies and prototype development for a number of devices.

\section{INTRODUCTION}

It is important to reorganise the role of the construction industry and its importance to the British economy. The value of construction output in 1989/90 was in excess of $f 45$ billion, representing more than $10 \%$ of the Gross Domestic National Product. During the same period the industry employed over one million people, accounting for approximately $5 \%$ of the total working population in this year.

It is becoming increasingly important that automation and robotics be introduced in to the construction industry. One of the serious problems facing the construction industry, is that young people are not being attracted to join the industry because they can see greater challenges from working in the high-tech industries, financial institutions and also in the service industry.

Although building and civil engineering sites are complex environments, demanding higher levels of adaptability from a wide range of plant and equipment systems, it is recognised that the gradual introduction of automation would be possible by improved planning and work scheduling and applying the principles of modern manufacturing to construction. The introduction of Information Technology tools to the design and construction process has started to take momentum and is bound to have considerable effect on U.K. construction practice. 


\section{THE U.K. ADVANCED ROBOTICS INITIATIVE}

Since its initiation in 1985, with the support of the Department of Trade and Industry (DTI), the three National croups with activities related to civil engineering and developments with the objectives in a number of studies and models and prototypes. The three introducing demonstrator feasibility and project definition Groups have completed required enabling technologies and studies covering the conceptual designs and the required outline specifications.

Project Definition stage led by Taylor Woodrow at the construction companies, two consisted of three manufacturer, two technology organsulting firms, a academic institutions. The PDS project was a wall climbing robot, adopting, completed in 1990, applied to both hardward and adopting a modular approach, comprise a set of self-contained coftware. The robot would a particular skill. A re-constituted aroup each capable of proposal to develop a number of group has prepared a integrated in a prototype building facade demstrators to be It is anticipated that the work of 1991 .

The Tunneliting Group led by British coal has considered tunnelling for broup led by British coal has considered with emphasis on a sying and civil engineering projects operation. The Group has systems approach and continuous and to demonstrate an AR production tunneloposal to develop offers continuous operation throu tunnelling system which automated sub-systems. Because of is likely that the commencement of the financial difficulties it The work of the Underwater Group may be delayed. project with Italy (EUREKA 191), incroup, which was a joint conceptual designs for Inspection robot for two demonstrator vehicles. Work and vehicle for inspection was based on a tethered, telerobotic structures, and for , maintenance and repair of offshore structures, and for assistance with subsea engineering
tasks. The second demonstrator was for a fully autonomous,
untethered vehicle for survey and untethered vehicle for survey and inspection of the sea the U.K. and Technomare from Italy. The were Ferranti oRE from progressed to the implementation stage.

\section{AUTOMATIC EXCAVATOR}

Work has been in progress at Lancaster University to develop the technologies required for the operation of an automatic excavator including hardware and software laboratory demelopment has included a one-fifth scale laboratory demonstrator model of an excavator arm which was configurations. various hardware and software A knowledge base governing the use and operation of excavators and other construction plant has also been developed. It is intended that this will be used as the lower level both the high level strategic knowledge and the operation of automatical knowledge structures required for the oferation of automated plant and equipment offsite. 
At the University of Wales college of Cardiff, an automatic soil stabilising machine for embankments and cuttings appliction has been developed using "soil nailing" technique. The soil nailer fires it steel nails into the soil using an air launching system based on one developed by Ferranti. This can shoot the nails $25 \mathrm{~mm}$ in diameter and up to $6 \mathrm{~m}$ long, into the soil at a rate of one per minute. Firing can be controlled so that the ends of the nails are arrested near the surface of the ground. The machine which operates hydraulically, incorporates microprocessor control of the firing mechanism.

\section{AUTOMATION OF MASONRY TASKS}

Since 1990 work has been in progress at the city University, London, to develop the enabling technology for robotisation of masonry task within quality assurance environment. The robot cell, which will be available for demonstration purposes early in the second half of 1991, will comprise a $5 \mathrm{~m} \times 0.6 \mathrm{~m}$ flat bed conveyor, mortar mixing, pumping and dispensing equipment, a rotating laser and a 5 axis gantry robot with a mechanical type block gripper.

The work is being supplemented by a CAD representation of the workplace providing the means for referencing, which is being updated for the possible relocation of objects and progress in the work assignment.

\section{INSPECTION OF NUCLEAR REACTORS}

At the Polytechnic of Portsmouth a climbing vehicle for the inspection of nuclear reactors has been developed. The device carries forward and reverse viewing TV cameras, their lights, a manipulator and its own cables up to a vertical rough steel surface vehicle pulling a considerable pay load.

The mechanism consists of two frames, an inner frame and an outer frame each of which carries four gripper feet. The outer frame has a pair of end-frames to which are fixed two short stroke pneumatic cylinders forming the "legs". The two end-frames are tied together by a stiff tie-rod on one side and the ends of a double rod, double-acting, pneumatic cylinder on the other. The cylinder body is free to slide backwards and forwards along its rod between the end frame, Each of the legs on the end-frames have a gripper foot attached with a limited play ball joint to allow the feet to be self aligning.

\section{FLEXIBLE MANUFACTURING SYSTEMS}

To determine the scope for employing flexible manufacturing systems, incorporating robotics technology, on construction sites, the University of Reading has just completed a study which also involved developing a model to illustrate the automation of installing cladding systems. The philosophy adopted was based on the assumption that construction should match the requirements for automation. 
The development was carried out with particular reference to the design and construction of low-rise, high-tech commercial and industrial buildings.

\section{TASK SELECTION FOR ROBOTIC EVALUATION}

In collaboration with a major U.K. contractor, the University of Nottingham has undertaken a study to ascertain which areas of the company's activities would benefit most from the deployment of robotic system. A technique called Qualitative Controlled Feedback (QCF) is being employed to survey a significant proportion of a company's site management, in order to evaluate the perceived benefits and restrictions associated with robotic systems.

Similar work in developing methodologies for appraising the feasible application of robotics in the construction process are also in progress at the London Southbank and Bristol Polytechnics. In these studies technical and economic issues are being addressed.

\section{APPLICATION OF INFORMATION TECHNOLOGY}

As in many Western countries the application of Information Technology to the automation of design and construction practice is gaining momentum in the industry supported by research and development in academic institutions. Expert and Knowledge Based Systems have been developed to deal with planning and site management, estimating and budgetting, design detailing and project management. Studies in these areas have been in progress at the Universities of Salford, Loughborough, Dundee, Leeds, Reading, Bristol, Nottingham, Manchester and the city University of London.

\section{CONCLUDING REMARKS}

Most of the U.K. development in the area of construction automation and robotics has essentially been in the form of laboratory demonstrators with a very few devices developed to the prototype stage. In the area of Advanced Robotics conceptual designs have been developed for a number of devices and it is anticipated that some will progress to the implementation stage.

As was mentioned in the paper entitled "Towards site 2000" there is a need for a test-bed site to be used as a proving ground for the introduction and integration of new technology incorporating prototype devices and new management tools.

\section{ACKNOWLEDGEMENTS}

I wish to acknowledge the invaluable assistance in the development of this paper from my colleagues in the U.K. 